OPEN ACCESS

Edited by:

Taku Takahashi,

Okayama University, Japan

Reviewed by:

Subhash C. Minocha,

University of New Hampshire, USA

Ji-Hong Liu,

Huazhong Agricultural University,

China

Ma Zhiying,

Hebei Agricultural University, China

*Correspondence:

Tomonobu Kusano

kusano@ige.tohoku.ac.jp

Specialty section: This article was submitted to

Plant Physiology,

a section of the journal

Frontiers in Plant Science

Received: 30 October 2015

Accepted: 08 February 2016

Published: 29 February 2016

Citation:

Sagor GHM, Zhang S, Kojima S, Simm S, Berberich T and Kusano T

(2016) Reducing Cytoplasmic

Polyamine Oxidase Activity

in Arabidopsis Increases Salt and Drought Tolerance by Reducing Reactive Oxygen Species Production and Increasing Defense Gene Expression. Front. Plant Sci. 7:214. doi: 10.3389/fpls.2016.00214

\section{Reducing Cytoplasmic Polyamine Oxidase Activity in Arabidopsis Increases Salt and Drought Tolerance by Reducing Reactive Oxygen Species Production and Increasing Defense Gene Expression}

\author{
G. H. M. Sagor ${ }^{1}$, Siyuan Zhang', Seiji Kojima ${ }^{1,2}$, Stefan Simm³ ${ }^{3}$, Thomas Berberich ${ }^{4}$ and \\ Tomonobu Kusano ${ }^{1 *}$ \\ ${ }^{1}$ Graduate School of Life Sciences, Tohoku University, Sendai, Japan, ${ }^{2}$ Frontier Research Institute for Interdisciplinary \\ Sciences, Tohoku University, Sendai, Japan, ${ }^{3}$ Department of Biosciences, Molecular Cell Biology of Plants, Goethe \\ University, Frankfurt am Main, Germany, ${ }^{4}$ Biodiversity and Climate Research Center, Laboratory Center, Frankfurt am Main, \\ Germany
}

The link between polyamine oxidases (PAOs), which function in polyamine catabolism, and stress responses remains elusive. Here, we address this issue using Arabidopsis pao mutants in which the expression of the five PAO genes is knocked-out or knockeddown. As the five single pao mutants and wild type (WT) showed similar response to salt stress, we tried to generate the mutants that have either the cytoplasmic PAO pathway (pao1 pao5) or the peroxisomal PAO pathway (pao2 pao3 pao4) silenced. However, the latter triple mutant was not obtained. Thus, in this study, we used two double mutants, pao1 pao5 and pao2 pao4. Of interest, pao1 pao5 mutant was $\mathrm{NaCl}-$ and drought-tolerant, whereas pao2 pao4 showed similar sensitivity to those stresses as WT. To reveal the underlying mechanism of salt tolerance, further analyses were performed. Na uptake of the mutant (pao1 pao5) decreased to $75 \%$ of WT. PAO activity of the mutant was reduced to $62 \%$ of WT. The content of reactive oxygen species (ROS) such as hydrogen peroxide, a reaction product of PAO action, and superoxide anion in the mutant became 81 and $72 \%$ of the levels in WT upon salt treatment. The mutant contained 2.8-fold higher thermospermine compared to WT. Moreover, the mutant induced the genes of salt overly sensitive-, abscisic acid (ABA)-dependent- and ABA-independent- pathways more strongly than WT upon salt treatment. The results suggest that the Arabidopsis plant silencing cytoplasmic PAOs shows salinity tolerance by reducing $R O S$ production and strongly inducing subsets of stress-responsive genes under stress conditions.

Keywords: Arabidopsis thaliana, drought stress, loss-of-function mutant, polyamine oxidase, reactive oxygen species, salinity stress 


\section{INTRODUCTION}

Polyamines (PAs) are aliphatic compounds with low molecular masses that are ubiquitously present in all living organisms. Bacteria primarily contain the PAs putrescine (Put) and spermidine ( $\mathrm{Spd}$ ), whereas some bacteria and mammalian cells also contain spermine (Spm; Tabor and Tabor, 1985; Cohen, 1998). In addition to these PAs, plants also contain another tetraamine, thermospermine (T-Spm), an isomer of Spm (Knott et al., 2007; Kakehi et al., 2008; Naka et al., 2010; Takano et al., 2012). PAs play important roles in numerous physiological processes. In plants, PAs are involved in embryogenesis, cell division, organogenesis, flowering and senescence, as well as responses to abiotic and biotic stresses (Groppa and Benavides, 2008; Kusano et al., 2008; Alcázar et al., 2010; Mattoo et al., 2010; Minocha et al., 2014; Berberich et al., 2015; Mo et al., 2015)

Polyamine homeostasis is governed by a dynamic balance between PA biosynthesis and catabolism. The plant PA biosynthetic pathway has been well documented (Bagni and Tassoni, 2001; Kusano et al., 2008; Fuell et al., 2010). Put biosynthesis starts with either the conversion of ornithine by ornithine decarboxylase (ODC) or arginine by arginine decarboxylase. Put is then converted to Spd by Spd synthase. This reaction requires another substrate, decarboxylated $S$-adenosylmethionine, which is synthesized from methionine via two sequential reactions catalyzed by methionine adenosyltransferase and $S$-adenosylmethionine decarboxylase, respectively. Spd is further converted to either Spm or T-Spm, which is catalyzed by Spm synthase or T-Spm synthase, respectively. It should be noted that Arabidopsis thaliana lacks a gene encoding ODC (Hanfrey et al., 2001). Accumulating evidence indicates that transgenic plants with increased PA levels (via overexpression of PA biosynthetic genes) have increased abiotic stress tolerance, whereas mutant plants deficient in PA biosynthesis are hypersensitive to abiotic stresses (Urano et al., 2003; Capell et al., 2004; Yamaguchi et al., 2006, 2007; Berberich et al., 2015 and the references therein).

Two additional enzymes, copper-containing amine oxidase $(\mathrm{CuAO})$ and polyamine oxidase (PAO), are also involved in PA catabolism (Bagni and Tassoni, 2001; Cona et al., 2006; Angelini et al., 2008; Moschou et al., 2012; Kusano et al., 2015; Liu et al., 2015; Wang and Liu, 2015). It was previously thought that $\mathrm{CuAO}$ only catalyzed the oxidation of diamines. For example, Put is oxidized to 4 -aminobutanal with concurrent production of $\mathrm{NH}_{3}$ and $\mathrm{H}_{2} \mathrm{O}_{2}$. However, it was recently revealed that some CuAOs also oxidize the triamine Spd (Planas-Portell et al., 2013). PAO is a flavin-adenine dinucleotide (FAD)-associated enzyme. Until 2006, it was believed that plant PAO catalyzed the conversion of Spd- and Spm-oxidation to 4-aminobutanal and $\mathrm{N}$-(3-aminopropyl)-4-aminobutanal, respectively, along with the production of 1,3-diaminopropane and $\mathrm{H}_{2} \mathrm{O}_{2}$ (Federico et al., 1990; Cona et al., 2006). The mode of this reaction is known as terminal catabolism. In addition to this process, plant PAO is also involved in a PA back-conversion pathway (Tavladoraki et al., 2006; Kamada-Nobusada et al., 2008; Moschou et al., 2008c; Takahashi et al., 2010; Fincato et al., 2011, 2012). This type of PAO reaction converts Spm and T-Spm to Spd, and/or further to Put, along with the production of 3-aminopropanal and $\mathrm{H}_{2} \mathrm{O}_{2}$. A. thaliana contains five $P A O$ genes, termed AtPAO1 to AtPAO5. These genes and their products have been extensively studied. AtPAO1 and AtPAO5 are located in the cytoplasm, whereas AtPAO2, AtPAO3, and AtPAO4 reside in peroxisomes (Tavladoraki et al., 2006; Kamada-Nobusada et al., 2008; Moschou et al., 2008c; Takahashi et al., 2010; Fincato et al., 2011, 2012; Ahou et al., 2014; Kim et al., 2014). Although the five AtPAOs differ in their spatio-temporal expression patterns and PA substrate specificity, all of these PAOs are involved in PA back-conversion, namely, AtPAO1 and AtPAO5 prefer T-spm and back-convert it to Spd, AtPAO4 is involved in Spm backconversion to Spd, not to Put, and AtPAO2 and AtPAO3 mainly convert Spd to Put. While a link between PA catabolism and abiotic and biotic stress responses has been described (Berberich et al., 2015; Roach et al., 2015, and references therein), most of these results were obtained using $\mathrm{CuAO}$ - or PAO-specific inhibitors.

The aim of this study was to uncover distinct role(s) of Arabidopsis PAOs in abiotic stress responses. We examined the growth responses of knock-out or knock-down mutants of AtPAOs under high salt and drought stress conditions. We found that the pao1 pao5 double mutant, but not the five single mutants or the pao2 pao4 double mutant, was tolerant to salt and drought stress. We investigated the reason behind the salt tolerance of pao1 pao5, finding that several genes in ABAdependent and -independent pathways were highly expressed in this mutant. We also measured the PAO activity and the amounts of hydrogen peroxide $\left(\mathrm{H}_{2} \mathrm{O}_{2}\right)$ and superoxide anion $\left(\mathrm{O}_{2}{ }^{-}\right)$in the pao1 pao5 mutant. The results of this study help elucidate a possible mechanism underlying the salt and drought tolerance of pao1 pao5.

\section{MATERIALS AND METHODS}

\section{Plant Materials and Growth Conditions}

Arabidopsis thaliana accession Col-0 [wild type (WT)] and T-DNA insertion lines Atpao1-2 (SAIL_822_A11), Atpao2-4 (SALK_046281), Atpao3-1 (GK209F07), Atpao4-1 (SALK_133599), and Atpao5-2 (SALK_053110), which were obtained from the Arabidopsis Biological Resource Center (Ohio State University, USA), were used in this study. The T-DNA insertion lines were designated pao1, pao2, pao3, pao4, and pao5, respectively. All seeds were surface sterilized with $70 \%$ ethanol for $1 \mathrm{~min}$ and $1 \%$ sodium hypochloride plus $0.1 \%$ Tween-20 for $15 \mathrm{~min}$, followed by extensive washing with sterile distilled water. Sterilized seeds were placed into pots containing a soil mix consisting of Vermiculite:SupermixA (1:1 v/v) or on half-strength MS (designated 1/2 MS in this study) 1.5\% agar plates ( $\mathrm{pH}$ 5.6) containing $1 \%$ sucrose and B5 vitamin (MP Biomedicals, Cat \# 2625149). The plants were grown at $22^{\circ} \mathrm{C}$ under a $14 \mathrm{~h}$ light/10 h dark photocycle.

\section{Chemicals}

Put, Spd, and Spm were purchased from Tokyo Kasei Co., Ltd. (Tokyo, Japan). T-Spm was chemically synthesized (Niitsu and 
Samejima, 1986). All other chemicals, which were analytical grade, were purchased from Sigma-Aldrich Corp. (St. Louis, MO, USA), Wako Pure Chemical Industries, Ltd. (Osaka, Japan), and Nacalai Tesque, Ltd. (Kyoto, Japan).

\section{Reverse Transcription-PCR (RT-PCR) and Quantitative RT-PCR (qRT-PCR) Analyses}

Total RNA was prepared from 2-week-old Arabidopsis seedlings using Sepasol-RNA I Super (Nacalai Tesque, Kyoto, Japan). First-strand cDNA was synthesized with ReverTra Ace (Toyobo Co. Ltd., Osaka, Japan) and oligo-dT primers. The qRT-PCR analysis was performed with Fast-Start Universal SYBR Green Master (ROX; Roche Applied Science, Mannheim, Germany) on a StepOne real-time PCR system (Life Technologies Japan, Tokyo, Japan). The two-step RT-PCR was performed with the following program: one cycle of $95^{\circ} \mathrm{C}$ for $10 \mathrm{~min}$, followed by 40 cycles of $95^{\circ} \mathrm{C}$ for $15 \mathrm{~s}$, and $60^{\circ} \mathrm{C}$ for $60 \mathrm{~s}$. Melting curves were generated after the 40 cycles by heating the samples to $95^{\circ} \mathrm{C}$ for $15 \mathrm{~s}$, followed by cooling to $60^{\circ} \mathrm{C}$ for $1 \mathrm{~min}$ and heating to $95^{\circ} \mathrm{C}$ for $15 \mathrm{~s}$. The amount of $\mathrm{cDNA}$ was calculated with the comparative $\Delta \Delta C_{\mathrm{T}}$ method (Schmittgen and Livak, 2008) with StepOne v2.1 (Applied Biosystems) using the housekeeping gene $C B P 20$, encoding cap-binding protein 20 (Supplementary Table S2) as a reference gene.

\section{Growth Response to High Salt and Drought Treatment}

High salt treatment: Sterilized Arabidopsis seeds were grown on $1 / 2$ MS agar plates containing different concentrations of $\mathrm{NaCl}(0,25,50,75$, and $100 \mathrm{mM})$. The plates were placed at a vertical position with an $85^{\circ}$ angle and incubated in a growth chamber at $22^{\circ} \mathrm{C}$ for 14 days. Drought treatment: Arabidopsis seeds were sown in pots containing soil mix (Vermiculite: Supermix A, $1: 1 \mathrm{v} / \mathrm{v}$ ) in a plant incubator at $22^{\circ} \mathrm{C}$ under a $14 \mathrm{~h}$ light $/ 10 \mathrm{~h}$ dark photocycle. Each pot contained $28 \mathrm{~g}$ of soil mix. The plants were supplied with $50 \mathrm{ml}$ of water once a week for 1 month. The plants were then divided into two groups: the first group was grown as before, and the second group was subjected to drought stress by withholding water for 2 weeks.

\section{Generation of the AtPAO Double Mutants}

The pao1 pao5 and pao2 pao4 double mutant plants were generated by crossing pao1 with pao5, and pao2 with pao4, respectively.

\section{Water Loss Assay}

Water loss assay was performed by the procedure described by Weigel and Glazebrook (2002). In brief, 2-week-old Arabidopsis seedlings were removed from the $1 / 2$ MS agar plates, and 25 seedlings per plate were placed onto dry filter paper. Their fresh weights were monitored every $10 \mathrm{~min}$ for $60 \mathrm{~min}$ after the onset of drought treatment. The fresh weights at the onset of the treatment were set at $100 \%$, and the relative water loss was determined.

\section{Measuring $\mathrm{Na}$ and $\mathrm{K}$ Levels}

Two-week-old seedlings grown on 1/2 MS agar medium were carefully removed from the plates, transferred to wet filter paper containing 1/2 MS liquid medium with or without $100 \mathrm{mM}$ $\mathrm{NaCl}$, and further incubated for 12 and $24 \mathrm{~h}$, respectively. The plant samples were collected, rinsed three times with deionized water, and dried at $65^{\circ} \mathrm{C}$ for 2 days. Dried plant samples were digested with $100 \%$ nitric acid at $130^{\circ} \mathrm{C}$ for $90 \mathrm{~min}$ and filtered, and the ion concentrations in the samples were analyzed by ICP spectrophotometry (iCAP 6000 series, ThermoFisher Scientific Inc., Waltham, MA, USA).

\section{PAO Activity Assay}

Polyamine oxidases activity was assayed as described by Liu and Liu (2004). Briefly, the enzyme extracts were prepared as follows: 2-week-old seedlings (approximately $0.2 \mathrm{~g}$ ) were homogenized in $100 \mathrm{mM}$ phosphate buffer ( $\mathrm{pH}$ 8.0) containing $20 \mathrm{mM}$ sodium ascorbate, $1 \mathrm{mM}$ pyridoxal-5' ${ }^{\prime}$-phosphate, $10 \mathrm{mM}$ DTT, $0.1 \mathrm{mM} \mathrm{Na} 2$ EDTA, and 0.1 mM PMSF (phenylmethylsulfonyl fluoride). The homogenate was centrifuged at $15,000 \times g$ for $60 \mathrm{~min}$ at $4^{\circ} \mathrm{C}$. The supernatant was used as the crude enzyme extract. The reaction mixture (total volume of $3.0 \mathrm{~mL}$ ) contained $0.1 \mathrm{~mL}$ of crude enzyme extract, $2.5 \mathrm{~mL}$ of $100 \mathrm{mM}$ sodium phosphate buffer ( $\mathrm{pH} 6.5$ ), $0.2 \mathrm{ml}$ of 4 -aminoantipyrine/ $N, N^{\prime}$ dimethylaniline, and $0.1 \mathrm{~mL}$ of horseradish peroxidase (POX; $250 \mathrm{U} / \mathrm{mL}$ ). The reaction was initiated by adding $200 \mathrm{mM}$ spermidine. A 0.01 change in absorbance at $555 \mathrm{~nm}$ was regarded as one enzyme activity unit.

\section{ROS Analyses}

$\mathrm{H}_{2} \mathrm{O}_{2}$ levels were determined as described by Messner and Boll (1994). Seedlings (approximately $200 \mathrm{mg}$ fresh weight) were homogenized in a pre-chilled mortar and pestle with $0.3 \mathrm{~mL}$ of $100 \mathrm{mM}$ potassium phosphate buffer ( $\mathrm{pH} 7.0$ ) containing $10 \%(\mathrm{w} / \mathrm{v})$ Polyclar. Each aliquot $(200 \mu \mathrm{L})$ of extract was combined with $10 \mu \mathrm{L}$ of horseradish POX [1 mg of enzyme (169-10791, Wako Chemical Co. Ltd.) dissolved in $100 \mathrm{mM}$ potassium phosphate buffer, 100 units/mg] and $10 \mu \mathrm{L}$ of $50 \mathrm{mM}$ (w/v) ABTS [2,20-azinobis(3-ethylobenzo-thiazoline-6-sulfonic acid) diammonium salt] solution. After 3 min of incubation, absorbance at $415 \mathrm{~nm}$ was measured using a spectrophotometer and compared with the values obtained from standard solutions containing specific amounts of $\mathrm{H}_{2} \mathrm{O}_{2}$ in $100 \mathrm{mM}$ potassium phosphate buffer ( $\mathrm{pH} 7.0)$.

$\mathrm{O}_{2}{ }^{-}$levels were determined based on its ability to reduce nitro blue tetrazolium (NBT) as described (Doke, 1983). In brief, seedlings were cut into pieces and immersed in $10 \mathrm{mM}$ potassium phosphate buffer ( $\mathrm{pH} 7.8$ ) containing $0.05 \%(\mathrm{w} / \mathrm{v})$ NBT and $10 \mathrm{mM} \mathrm{NaN}_{3}$, and incubated for $1 \mathrm{~h}$ at room temperature. After incubation, $2 \mathrm{~mL}$ of the reaction solution was heated at $85^{\circ} \mathrm{C}$ for $15 \mathrm{~min}$ and cooled rapidly. The optical density at $580 \mathrm{~nm}$ was recorded, and the $\mathrm{O}_{2}{ }^{-}$content was expressed as the increase in absorbance/g dry weight.

In situ accumulation of $\mathrm{O}_{2}^{-}$and $\mathrm{H}_{2} \mathrm{O}_{2}$ was detected by histochemical staining with NBT and diaminobenzidine (DAB), 
respectively, according to the procedure described by RomeroPuertas et al. (2004) with minor modifications. In brief, 2-weekold Arabidopsis seedlings grown on 1/2 MS agar medium were carefully removed from the medium, transferred to wet filter paper containing 1/2 MS medium solution either with or without $100 \mathrm{mM} \mathrm{NaCl}$, and further incubated for $12 \mathrm{~h}$. For $\mathrm{O}_{2}{ }^{-}$detection, the seedlings were immersed in $2 \%$ NBT solution dissolved in $10 \mathrm{mM}$ phosphate buffer ( $\mathrm{pH} 7.8$ ) at room temperature. The immersed leaves were illuminated for $2 \mathrm{~h}$ until dark spots appeared, which are characteristic of blue formazan precipitates. To detect $\mathrm{H}_{2} \mathrm{O}_{2}$, another set of samples was immersed in DAB solution ( $1 \mathrm{mg} \mathrm{mL}^{-1}$ ) that was freshly prepared in $10 \mathrm{mM}$ phosphate buffer ( $\mathrm{pH} 7.8$ ) and incubated at room temperature for $8 \mathrm{~h}$ under continuous light until brown spots, which are derived from the reaction of DAB with $\mathrm{H}_{2} \mathrm{O}_{2}$, were observed. For both staining methods, the seedlings were bleached in $100 \%$ ethanol, followed by $70 \%$ ethanol, and observed under a microscope (LG-PS2, Olympus).

\section{Ion Leakage Assay}

Conductivity was measured with a MultiLine Multi 3410 IDS instrument equipped with a TetraCon 925 conductivity cell (WTW Wissenschaftlich-Technische Werkstätten $\mathrm{GmbH}$, Weilheim, Germany). Five seedlings each with or without $100 \mathrm{mM} \mathrm{NaCl}$ treatment were rinsed five times with distilled water. The rosette leaves removed from seedlings were incubated in a $15 \mathrm{~mL}$ tube with $5 \mathrm{~mL}$ of distilled water for $24 \mathrm{~h}$ at $22^{\circ} \mathrm{C}$ before measuring (Cond1). Total conductivity (Cond2) was obtained after heating the tubes in boiling water for $20 \mathrm{~min}$. Electrolyte leakage was expressed as percentage of total conductivity. Leakage was calculated as: Cond $1 /$ Cond $2 \times 100$.

\section{Enzyme Activity Assay}

The activities of catalase (CAT; EC 1.11.1.6), POX (EC 1.11.1.7), superoxide dismutase (SOD; EC 1.15.1.1) and ascorbate peroxidase (APX; EC 1.10.3.3) were tested in $100 \mathrm{mM} \mathrm{NaCl}$ treated and untreated WT and pao1 pao5 mutant plants. Five seedlings each were blotted dry, weighed and homogenized on ice in the respective extraction buffer $(4 \mu \mathrm{L} / \mathrm{mg}$ fresh weight) in a $1.5 \mathrm{~mL}$ tube with a little sea sand and a pestle. Fifty $\mathrm{mM}$ K-phosphate-buffer, $\mathrm{pH} 7.5$, was used as extraction buffer for CAT and SOD. For APX assays $50 \mathrm{mM} \mathrm{K}$-phosphate-buffer, $\mathrm{pH}$ 7.0, containing $1 \mathrm{mM} \mathrm{Na-ascorbate}$ was used for extraction. For POX assays the assay buffer of the assay Kit (Sigma-Aldrich) was used. After centrifugation at $15,000 \times \mathrm{g}$, for $10 \mathrm{~min}$ at $4^{\circ} \mathrm{C}$, the supernatants were transferred to fresh tubes and kept on ice until use. All enzyme activities were measured spectrophotometrically (Hitachi U-2000). The results are presented as relative activities compared to untreated WT seedlings. CAT activity was estimated by the breakdown of $\mathrm{H}_{2} \mathrm{O}_{2}$ (Beers and Sizer, 1952). Briefly, $10 \mu \mathrm{L}$ of extract was used in a total volume of $1 \mathrm{~mL}$ extraction buffer containing $10 \mathrm{mM} \mathrm{H} \mathrm{H}_{2} \mathrm{O}_{2}$ and the decrease of $\mathrm{H}_{2} \mathrm{O}_{2}$ was monitored by change in the absorbance at $240 \mathrm{~nm}$. The activity per mg tissue was calculated according to Beers and Sizer (1952). POX activity was measured using a commercial kit (POX Activity Assay Kit, Sigma-Aldrich). Four $\mu \mathrm{L}$ of extract was used for the colorimetric assay $(570 \mathrm{~nm})$ in a total volume of $100 \mu \mathrm{L}$ as described in the manual using a microcuvette at $25^{\circ} \mathrm{C}$. A standard curve was used to calculate enzyme activity per mg tissue. SOD was assayed according to McCord and Fridovich (1969) through inhibition of the reduction of oxidized cytochrome $\mathrm{c}$ by SOD in a coupled system, using xanthine and xanthine oxidase. Between 5 and $10 \mu \mathrm{L}$ of extract were used and the absorbance at $550 \mathrm{~nm}$ was monitored. The percentage of inhibition was calculated and used to express the activity in units/g FW. APX activity was tested with $10 \mu \mathrm{L}$ of extract in a total volume of $1 \mathrm{~mL}$ reaction mixture by monitoring the oxidation rate of ascorbate at $290 \mathrm{~nm}$ according to Nakano and Asada (1987).

\section{PA Analysis by High Performance Liquid Chromatography (HPLC)}

PA extraction, derivatization, and analysis by HPLC were performed as described by Naka et al. (2010) and Sagor et al. (2015). In brief, plant samples (0.3-0.5 g per sample) were pulverized with a mortar and pestle under liquid nitrogen. Five volumes $(2.5 \mathrm{~mL}$ per $0.5 \mathrm{~g}$ of plant sample) of $5 \%(\mathrm{v} / \mathrm{v})$ cold perchloric acid were added to the resulting fine powders. The mixtures were transferred to plastic tubes and kept on ice for $1 \mathrm{~h}$. After centrifugation at $15,000 \times g$ for $30 \mathrm{~min}$ at $4^{\circ} \mathrm{C}$, the supernatants were combined and filtered using a filter syringe (pore size, $0.2 \mu \mathrm{m}$ ). One milliliter of $2 \mathrm{~N} \mathrm{NaOH}$ was added to $1.5 \mathrm{~mL}$ of plant extract, the mixture was vortexed, $10 \mu \mathrm{L}$ of benzoyl chloride was added, and mixed again followed by incubation at room temperature for $20 \mathrm{~min}$, and then $2 \mathrm{~mL}$ of saturated $\mathrm{NaCl}$ was added. After the addition of $2 \mathrm{~mL}$ of diethyl ether, samples were vigorously mixed and then centrifuged at $3,000 \times g$ for $10 \mathrm{~min}$ at $4^{\circ} \mathrm{C}$ for phase-separation. An aliquot $(1.5 \mathrm{~mL})$ of the organic solvent phase was evaporated and the residue was resuspended in $50 \mu \mathrm{L}$ of methanol.

Benzoylated PAs were analyzed with a programmable Agilent 1200 liquid chromatograph using a reverse-phase column (4.6 mm × $250 \mathrm{~mm}$, TSK-GEL ODS-80Ts, TOSOH, Tokyo, Japan) and detected at $254 \mathrm{~nm}$ as described (Sagor et al., 2015).

\section{Statistical Analysis}

All experiments were performed with at least three biological samples unless mentioned. Data analysis was performed using the statistical tools (Student's $t$-test) of Microsoft Excel software.

\section{RESULTS}

\section{Five Arabidopsis Single pao Mutants Exhibit WT-Like Responses to High Salt Stress}

First, we confirmed the transcript levels of the five PAO genes in WT and the pao mutants by real-time reverse transcriptionpolymerase chain reaction (qRT-PCR) using the primers listed in Supplementary Table S1. The pao1 and pao5 mutants appeared to be knock-out mutants, whereas pao2, pao3, and pao4 were likely knock-down mutants (Kim et al., 2014). We tested the $\mathrm{NaCl}$ 
sensitivity of these pao mutants by plating sterilized seeds on MS agar medium with or without $100 \mathrm{mM} \mathrm{NaCl}$ and incubating them for 14 days. Under non-stressed conditions, the relative growth of the pao mutants was similar to WT, and no difference in growth was observed among mutants (Supplementary Figure $\mathrm{S} 1 \mathrm{~A})$. When grown on $100 \mathrm{mM} \mathrm{NaCl}$, primary root growth was inhibited to a similar extent among WT and all pao mutants (Supplementary Figures S1A,B).

\section{Growth Responses of pao1pao5 and pao2pao4 Mutants Under High Salt Stress}

Of the five AtPAOs, two (AtPAO1 and AtPAO5) localize to the cytoplasm and three (AtPAO2, AtPAO3, and AtPAO4) reside in peroxisome. Thus, we first aimed to generate the mutants which either lost cytoplasmic PAO activity (pao1 pao5) or lost peroxisomal PAO activity (pao2 pao3 pao4) (Andronis et al., 2014). We obtained two pao double mutants, pao1 pao5 and pao 2 pao4, by crossing. We further tried to get a triple mutant, pao2 pao3 pao4, by crossing pao 2 pao 4 and pao3, three times, but failed to get it. Therefore, we used the two double mutants, pao1 pao5 and pao 2 pao4, in this study. We confirmed the identity of the mutants by PCR, finding that both double mutants contained T-DNA inserted in both DNA strands of PAO1 and PAO5 and of $P A O 2$ and $P A O 4$, respectively (Supplementary Figure S2). We then examined $P A O$ transcript levels in the mutants. In pao1pao5, AtPAO2, AtPAO3, and AtPAO4 transcript levels were a bit higher than those of WT, whereas AtPAO1 and AtPAO5 transcript levels were reduced to 20 and $0.7 \%$, respectively, compared to WT (Supplementary Figures S3A,B). In pao2 pao4, the levels of AtPAO1, AtPAO2, AtPAO3, AtPAO4, and AtPAO5 transcripts were approximately $150,0.03,170,18$, and $160 \%$ those of WT, respectively (Supplementary Figures S3A,C), further confirming the identity of both mutants. Next, we tested the growth of these double mutants under high salt conditions. Interestingly, pao1 pao5 was less sensitive to $\mathrm{NaCl}$ than WT (Figures 1A,B), whereas pao2 pao4 showed WT levels of $\mathrm{NaCl}$ sensitivity (Figures 1C,D). The use of increasing concentrations of $\mathrm{NaCl}$ confirmed the $\mathrm{NaCl}$ tolerance of paol pao5. Finally, the primary roots of the mutant were significantly longer $(140 \sim 178 \%)$ than those of WT when grown in 50-100 $\mathrm{mM} \mathrm{NaCl}$ (Figures 1E,F). Therefore, the pao1 pao5 mutant is $\mathrm{NaCl}$ tolerant compared to WT.

\section{Growth Responses of pao1pao5 to Drought Stress}

We also tested the growth responses of the pao1 pao5 mutant to drought stress, along with those of WT, pao1, and pao5. Under well-watered conditions, WT, pao1, pao5, and pao1 pao5 grew at comparable rates. By contrast, once the water supply was stopped, the double mutant lived longer than WT and both single mutants (Figure 2A, Supplementary Figure S4). Next we measured water loss in these plants upon dehydration. At $20 \mathrm{~min}$ after the onset of dehydration, the double mutant still retained approximately $50 \%$ of its water content, whereas WT and the single mutants lost more than $60 \%$ of their water contents (Figure 2B).

\section{$\mathrm{Na}$ and $\mathrm{K}$ (Potassium) Contents in WT, pao1, pao5, and pao1pao5 Plants Exposed to High Salt}

At $12 \mathrm{~h}$ after $\mathrm{NaCl}$ treatment, the $\mathrm{Na}$ and $\mathrm{K}$ contents in pao5 mutant were about 70 and $80 \%$ levels compared to those of WT, whereas those in pao1 pao5 double mutant were comparable to those of WT (Figures 3A,B). At $24 \mathrm{~h}$ of stress treatment, the $\mathrm{Na}$ contents in pao1, pao5, and pao1 pao5 mutants were similarly lower (74-79\%) than in WT (Figure 3A), whereas the K contents were similar among all plant samples (Figure 3B).

\section{Changes in PA Contents in WT and pa01pao5 Plants Exposed to High Salt}

In WT, Put levels increased to $180 \%$ at $6 \mathrm{~h}$ after $100 \mathrm{mM}$ $\mathrm{NaCl}$ treatment, and then gradually decreased until $24 \mathrm{~h}$ but still retained $145 \%$ level. In the pao 1 pao5 mutant, Put content remained at constant levels $(6 \mathrm{nmol} / \mathrm{g} \mathrm{FW})$ until $12 \mathrm{~h}$ after $\mathrm{NaCl}$ treatment and then increased to ca. $9 \mathrm{nmol} / \mathrm{g} \mathrm{FW}$ at $24 \mathrm{~h}$ (Supplementary Figure S5A). Spd contents gradually decreased to around $75 \%$ levels in both WT and the mutant upon high salt exposure, with not much difference observed between lines (Supplementary Figure S5B). T-Spm content in pao1 pao5 was 2.8-folds higher than that of WT under physiological condition (Supplementary Figure S5C). T-Spm content decreased to onethird level in $\mathrm{WT}$ at $24 \mathrm{~h}$ after $\mathrm{NaCl}$ treatment. Even in the double mutant, the T-Spm level decreased to $80 \%$ at $24 \mathrm{~h}$ after $\mathrm{NaCl}$ treatment but was still 6.5 -folds higher than that of WT (Supplementary Figure S5C). Spm contents in both WT and pao1 pao5 increased 170 and 150\% levels, respectively, at $24 \mathrm{~h}$ after salt treatment, although their modulation patterns differed (Supplementary Figure S5D).

\section{Comparison of PAO Activity, $\mathrm{H}_{2} \mathrm{O}_{2}$ Levels, and Super Oxide Anion Levels in WT vs. pao1, pao5, and pao1pao5 Plants Exposed to High Salt}

We then measured PAO activity in the plants, finding that under non-stressed conditions, the highest to lowest relative PAO activity occurred in WT $>$ pao1 $>$ pao5 $>$ pao1 pao5 (Figure 4A). Under $\mathrm{NaCl}$ treatment, PAO activity in WT increased approximately 1.5 -fold. After $\mathrm{NaCl}$ treatment, the plants with the highest to lowest relative PAO activity were again $\mathrm{WT}>$ pao1 > pao5 > pao1 pao5 (Figure 4A). The relative PAO activity of the double mutant decreased to $62 \%$ of that of WT after $\mathrm{NaCl}$ treatment (Figure 4A). Since $\mathrm{H}_{2} \mathrm{O}_{2}$ is produced through the action of PAO, we examined $\mathrm{H}_{2} \mathrm{O}_{2}$ levels in plants after $\mathrm{NaCl}$ treatment. The plants with the highest to lowest $\mathrm{H}_{2} \mathrm{O}_{2}$ levels were WT $>$ pao1 $=$ pao5 $>$ pao1 pao5 under physiological- and high salt conditions. $\mathrm{H}_{2} \mathrm{O}_{2}$ content in the double mutant was $81 \%$ of that of WT in normal condition (Figure 4B). $\mathrm{H}_{2} \mathrm{O}_{2}$ levels in WT, pao1 and pao5 increased about $16-21 \%$ after $\mathrm{NaCl}$ treatment, whereas that in the double mutant increased $8 \%$ upon salt treatment (Figure 4B). We also examined the super oxide anion $\left(\mathrm{O}_{2}{ }^{-}\right)$levels in these plants. Under control conditions, $\mathrm{O}_{2}{ }^{-}$levels were slightly lower (86\%) in pao1 pao5 


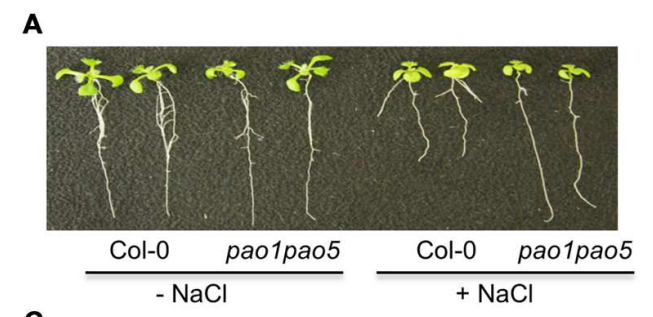

C

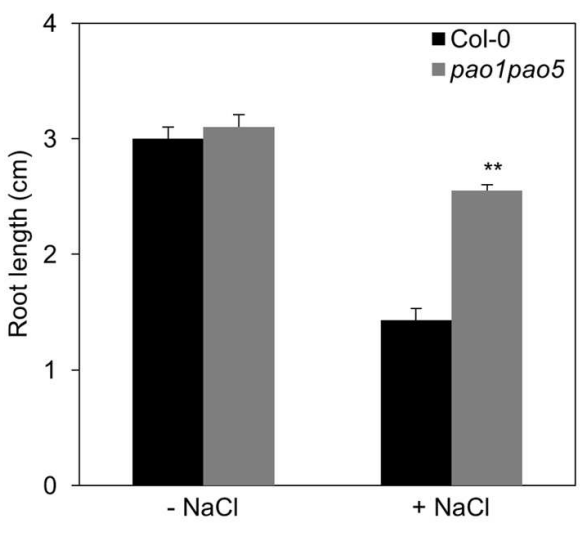

B

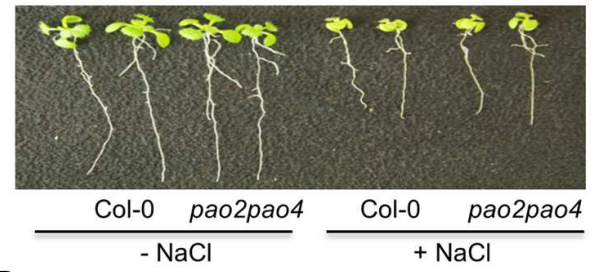

D

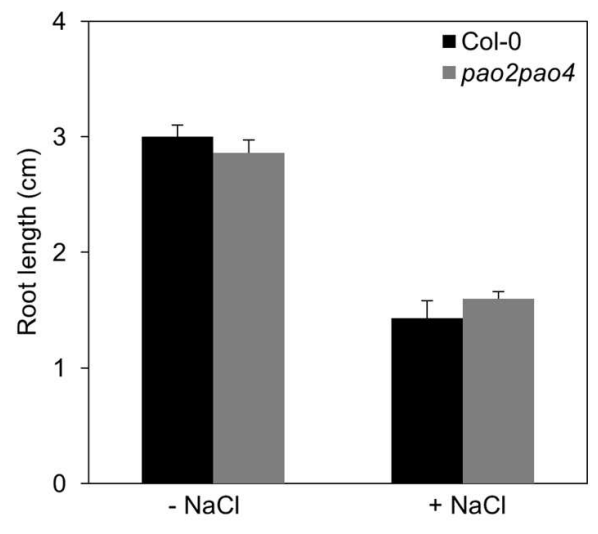

E
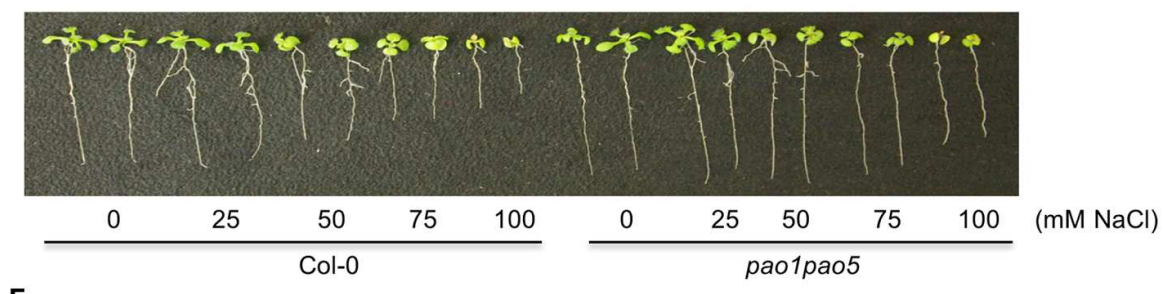

$\mathbf{F}$

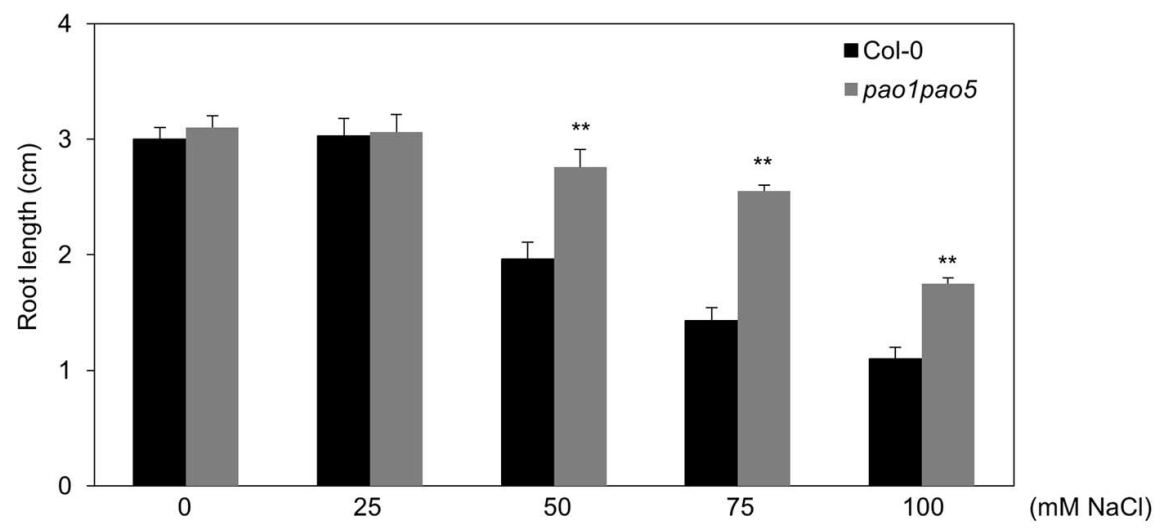

FIGURE 1 | Growth responses of pao1 pao5 and pao2 pao4 to various concentrations of $\mathrm{NaCl}$. (A) Growth response of pao1 pao5 to 100 mM $\mathrm{NaCl}$. (B) Root lengths of WT and pao1 pao5 with or without $100 \mathrm{mM} \mathrm{NaCl}$ after a 14 days incubation. The values indicate means $\pm \mathrm{SE}(n=5)$. (C) Growth response of pao2 pao4 to $100 \mathrm{mM} \mathrm{NaCl}$. (D) Average root length of WT and pao2 pao4 with or without $100 \mathrm{mM} \mathrm{NaCl}$ after a 14 days incubation. The values indicate means \pm SE $(n=5)$. (E) Growth responses of WT and pao1pao5 plants to different NaCl levels in MS agar medium. Two representative plants, each incubated for 14 days, were photographed. (F) Root length of WT and pao1 pao5 grown on MS agar medium containing 0, 25, 50, 75, and 100 mM NaCl for 14 days. The values indicate means \pm SE $(n=5)$. Asterisk indicates significant difference between WT $(\mathrm{Col}-0)$ and pao1 pao5; ** $P<0.01$

than in WT and the single mutants. Upon $\mathrm{NaCl}$ treatment, $\mathrm{O}_{2}^{-}$ levels increased approximately 1.4-fold in WT and in both single mutants, whereas in the double mutant, $\mathrm{O}_{2}^{-}$level increased to1.2-fold (Figure 4C). Thirty $\%$ of $\mathrm{O}_{2}{ }^{-}$production decreased in the $\mathrm{NaCl}$-treated double mutant compared to that in $\mathrm{NaCl}$ treated WT, pao1 and pao5 mutants (Figure 4C). Collectively, 
A
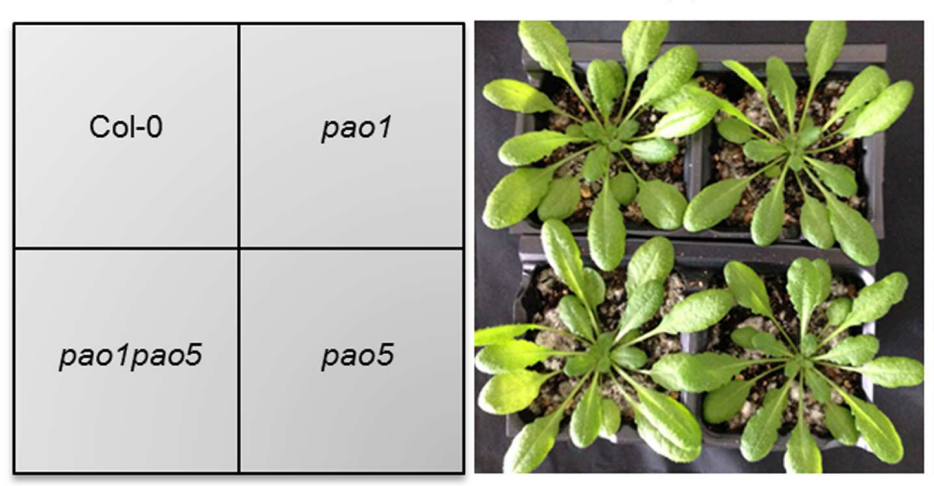

B

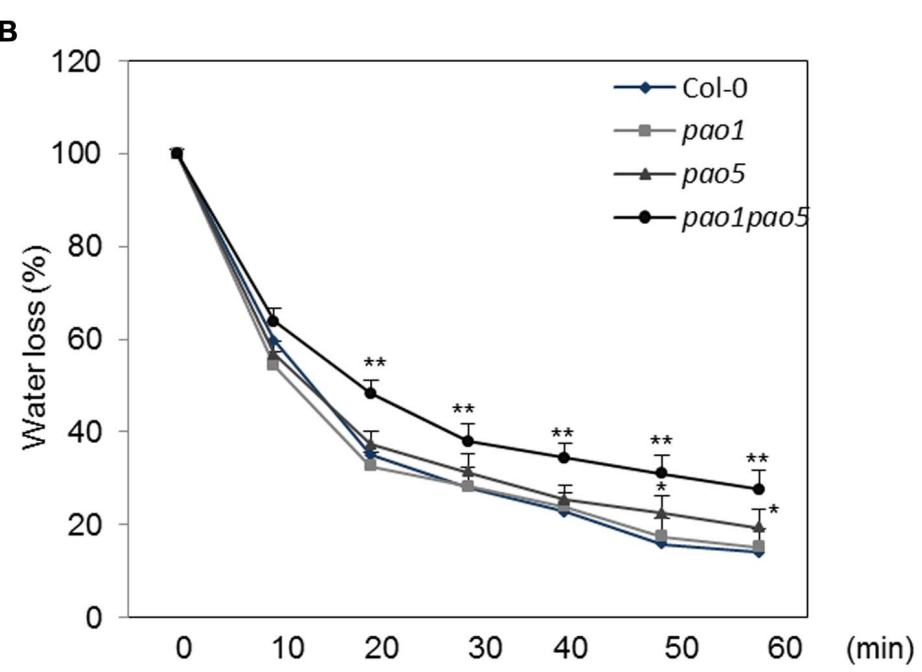

$(-)$ water

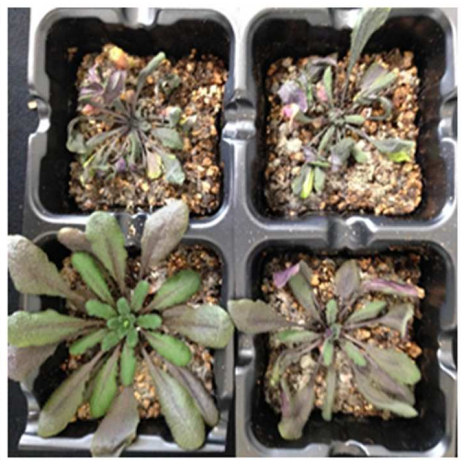

FIGURE 2 | Drought responses of WT, pao1, pao5, and pao1 pao5 plants, and their rates of water loss. (A) Left, WT, pao1, pao5, and pao1 pao5 plants were grown in Vermiculite/Supermix A (1:1 v/v) for 28 days. Right, water supply was stopped at 28 days and the plants were further incubated for 14 days. (B) Water loss rate from WT, pao1, pao5, and pao1 pao5 plantlets. Two-week-old plantlets $(n=25)$ grown on MS agar medium were carefully detached from the plates and placed onto dry filter paper (Whatman \#2) and their fresh weight was measured at various time intervals. Asterisk indicates significant difference: ${ }^{*} P<0.05$, ${ }^{* *} P<0.01$.


FIGURE 3 | $\mathrm{Na}$ (A) and K (B) contents in WT, pao1, pao5, and pao1 pao5 plants exposed to $100 \mathrm{mM}$ NaCl. Asterisk indicates significant difference: ${ }^{*} P<0.05,{ }^{* *} P<0.01$. 

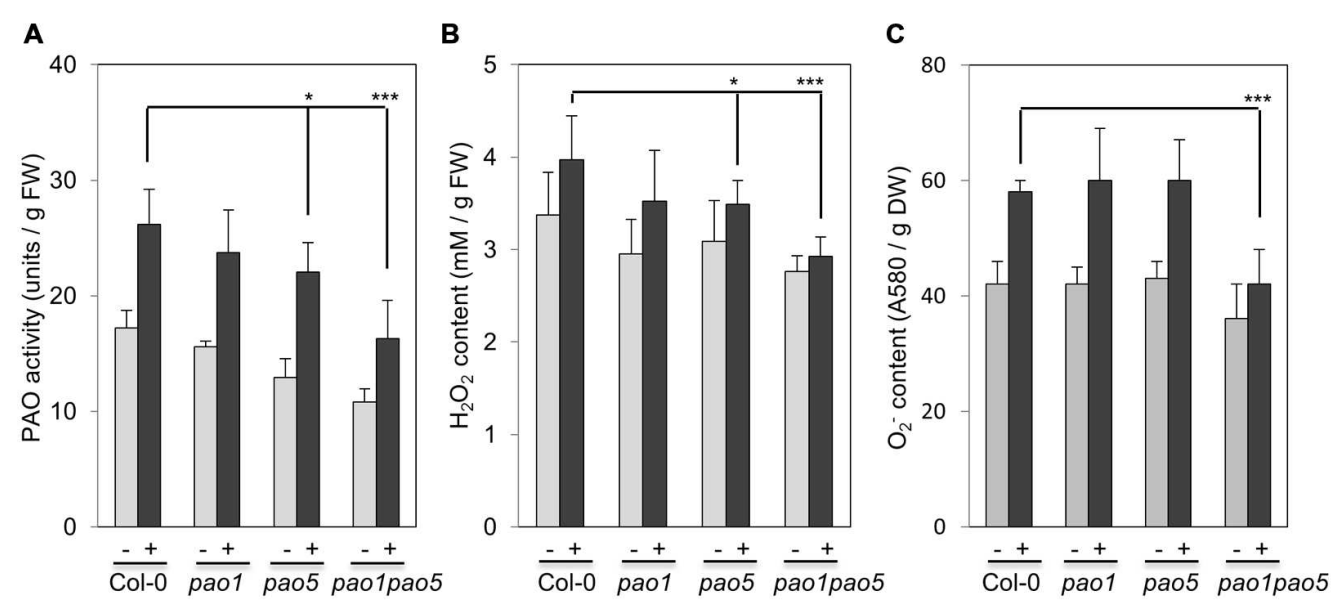

FIGURE 4 | Comparison of PAO activity (A), $\mathrm{H}_{2} \mathrm{O}_{2}$ production (B), and $\mathrm{O}_{2}{ }^{-}$production (C) in WT, pao1, pao5 single mutants, and pao1 pao5 double mutant upon $\mathrm{NaCl}$ treatment. Asterisk indicates significant difference: ${ }^{*} P<0.05,{ }^{* * *} P<0.001$.

the results indicate that the increased $\mathrm{H}_{2} \mathrm{O}_{2}$ and $\mathrm{O}_{2}{ }^{-}$levels in the $\mathrm{NaCl}$-treated double mutant were less significant in relative to those in NaCl-treated WT and the single mutants. The results were further supported by histochemical detection of $\mathrm{O}_{2}{ }^{-}$and $\mathrm{H}_{2} \mathrm{O}_{2}$ (Figure 5). In WT, pao1, and pao5 single mutants, intense blue formazan precipitates were detected after $\mathrm{NaCl}$ treatment, while such signals were weak in the pao1 pao5 double mutant, which is indicative of less $\mathrm{O}_{2}{ }^{-}$accumulation (Figures $5 \mathbf{A}, \mathbf{B}$ ). Similarly, intense brown precipitates were observed in WT and both single mutants treated with $\mathrm{NaCl}$, whereas those in the double mutant were faint, indicating lower $\mathrm{H}_{2} \mathrm{O}_{2}$ accumulation in the double mutant (Figures 5C,D). The pao2 pao4 mutant seemed to produce the similar levels of $\mathrm{O}_{2}{ }^{-}$and $\mathrm{H}_{2} \mathrm{O}_{2}$ compared to those of WT upon $\mathrm{NaCl}$ treatment (Supplementary Figures S6A,B).

\section{Changes of Electrolyte Leakage and Antioxidant Enzyme Activities, and Expressional Changes of Antioxidant Enzyme Genes in WT and pao1 pao5 Mutant}

We compared the leakage rate of electrolytes between WT and the double mutant upon $\mathrm{NaCl}$ treatment but could not see a clear difference. Upon $\mathrm{NaCl}$ treatment, both WT and the mutant leaked the electrolytes $\sim 30 \%$ more compared to the nontreated seedlings (Figure 6A). Next we compared the activities of antioxidant enzymes, catalase (CAT), ascorbate peroxidase (APX), SOD and POX of WT and the mutant. The activities of CAT, APX, and SOD were enhanced $\sim 20-30 \%$ in WT upon $\mathrm{NaCl}$ treatment, while the POX activity was not changed in WT (Figure 6B). In the mutant, CAT and POX activities were $\sim 20-$ $30 \%$ higher than those of non-stressed WT, but not modulated by salt treatment. Net SOD activity in the mutant increased to $140 \%$ levels upon salt treatment as like WT (Figure 6B).

Furthermore we compared the transcript levels of CAT, APX, and $S O D$ genes in WT and the mutant. Among three CAT genes,
CAT1 and CAT3 were induced 0.2-fold and 2-fold levels in WT by salt treatment, whereas they were induced 2.9 and 3.7-fold levels in the double mutant. CAT2 transcripts decreased to $~ 50 \%$ levels both in WT and the mutant after $6 \mathrm{~h}$ salt treatment (Figure 7A). Of ascorbate peroxidase genes ( $A P X 1$ to -4$)$, the transcript levels of $A P X 2, A P X 3$, and APX4 kept constant or decreased to 50\% levels, respectively (Figure 7B). APX1 and stromal ascorbate peroxidase gene $(s A P X)$ behaved similarly. Namely upon salt stress $A P X 1$ and $s A P X$ transcripts increased to 1.4 and 1.2-fold, respectively, in $\mathrm{WT}$, and their basal transcript levels in the double mutant were 70 and $80 \%$ compared to those of WT and they accumulated to 170 and $160 \%$ levels in relative to those of nonstressed WT (Figure 7B). Of three plastidial Fe-SOD genes, $\mathrm{Fe}$ SOD2 and Fe SOD3 transcripts increased to 1.6-fold levels in the double mutant (Figure 7C). Mitochondrial Mn SOD was induced to 1.6-fold levels only in the mutant after salt treatment (Figure 7C). Cu/Zn SOD1 and $\mathrm{Cu} / \mathrm{Zn}$ SOD2 were not much modulated at the transcriptional level by salt treatment, whereas $\mathrm{Cu} / \mathrm{Zn}$ SOD3 was induced to 1.8 -fold levels both in WT and the mutant (Figure 7C).

\section{Expressional Changes of Key Genes Involved in Adaptation to High Salt Stress in WT and pao1 pao5 Mutant}

Previous investigations have revealed several genes encoding key components involved in adaptation to high salt conditions in Arabidopsis (Zhu, 2002). One such pathway is the $\mathrm{Ca}^{2+}$ dependent Salt Overly Sensitive (SOS) pathway, which consists of three components: SOS3 (calcium binding protein), SOS2 (SNF1-like protein kinase), and SOS1 (plasma membranelocalized $\mathrm{Na}^{+} / \mathrm{H}^{+}$antiporter; Mahajan et al., 2008; Ji et al., 2013). In addition, HKT1 (high affinity potassium transporter1 localized in plasma membrane) and NHX1 (vacuolar-localized $\mathrm{Na}^{+} / \mathrm{H}^{+}$exchanger) play important roles in $\mathrm{Na}^{+}$uptake and $\mathrm{Na}^{+}$-sequestration to vacuole, respectively (Apse et al., 1999). We therefore measured the transcript levels of genes encoding 

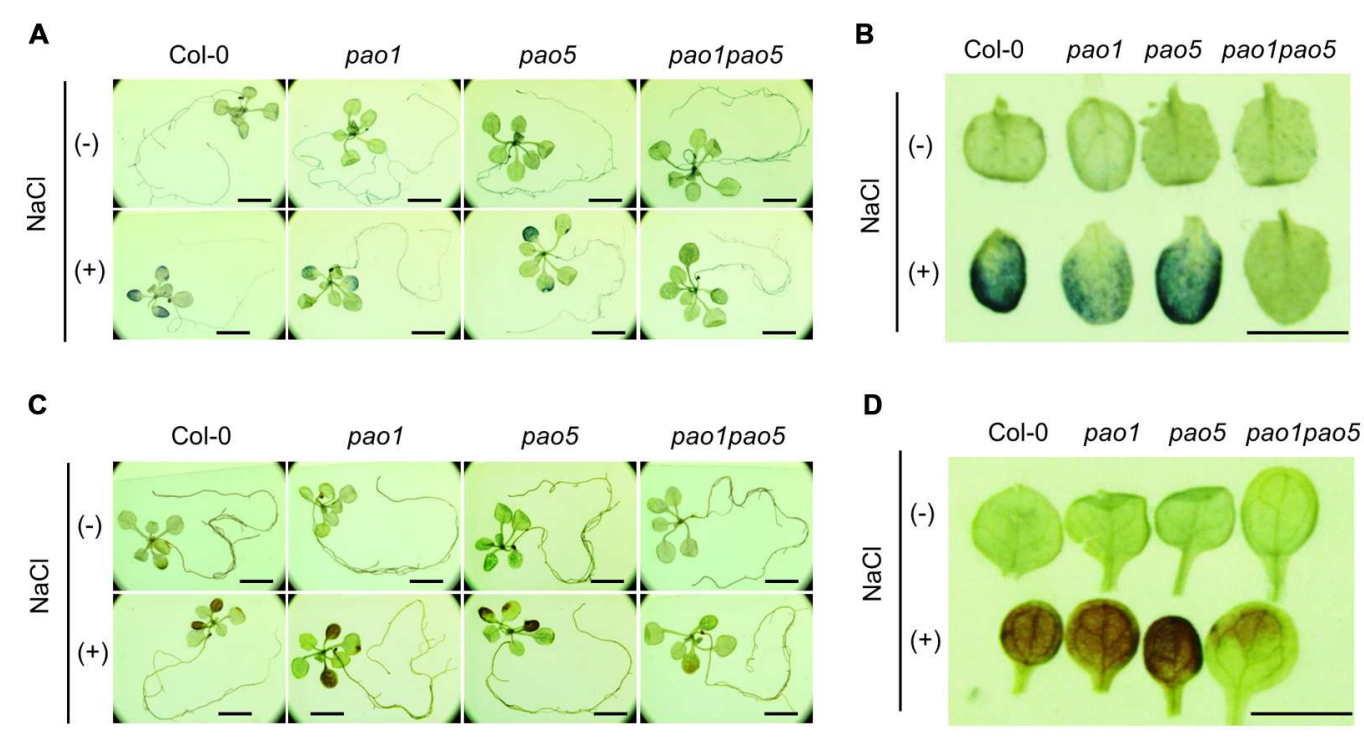

FIGURE 5 | Histochemical analysis of $\mathrm{O}_{2}{ }^{-}$(A,B) and $\mathrm{H}_{2} \mathrm{O}_{2}$ (C,D) accumulation in WT, pao1, pao5, and pao1 pao5 after NaCl treatment. (A,B) NBT staining; (C,D) DAB staining. (A,C) Stained whole seedling; (B,D) enlarged cotyledon leaves. Bar indicates $1 \mathrm{~mm}$.
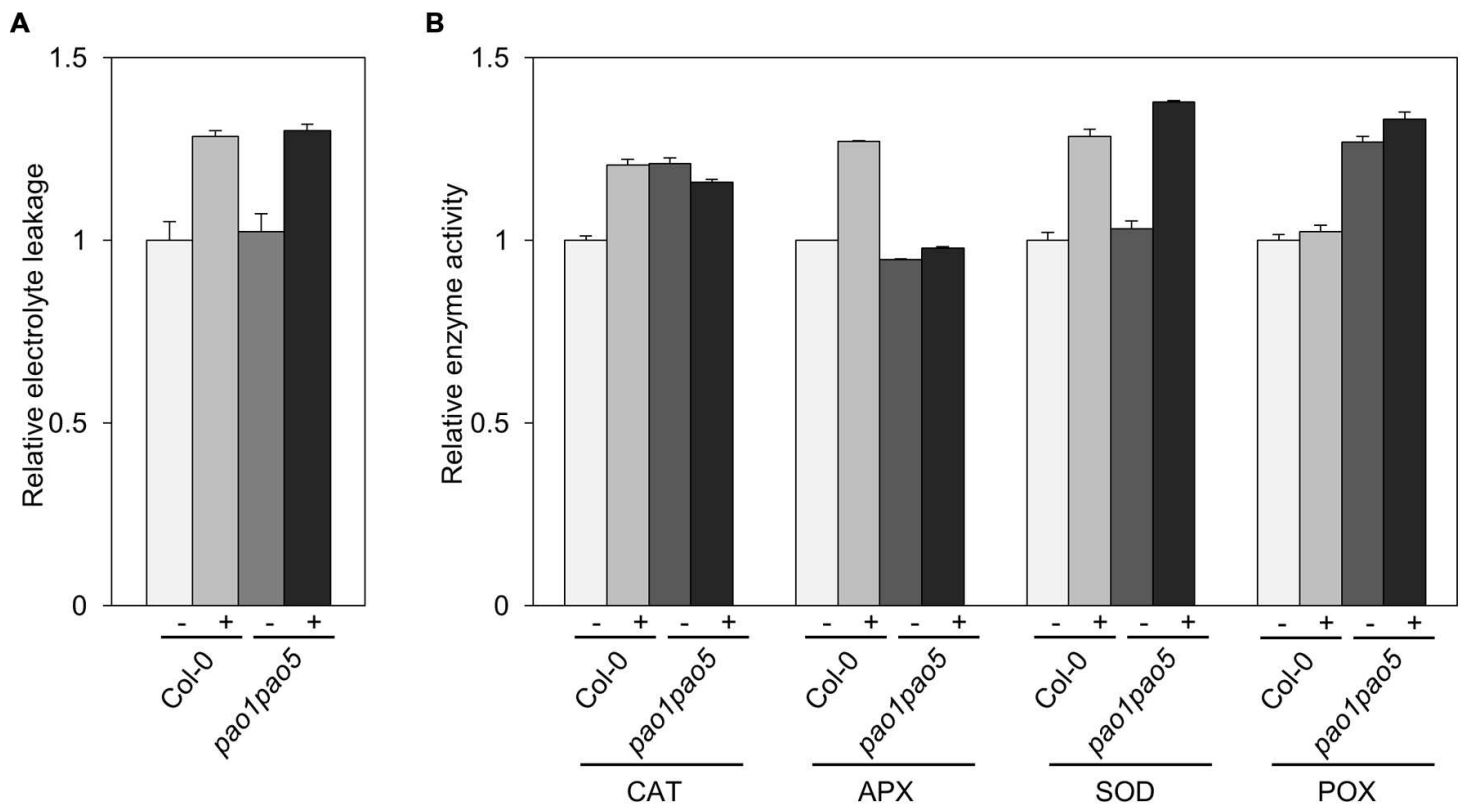

FIGURE 6 | Biochemical analyses of WT and pao1 pao5 mutant upon high salt stress. (A) Electrolyte leakage; (B) Enzyme activities of catalase (CAT), ascorbate peroxidase (APX), superoxide dismutase (SOD), and peroxidase (POX) in WT and the double mutant with or without $100 \mathrm{mM} \mathrm{NaCl}$ treatment for $6 \mathrm{~h}$.

these key components. Among SOS pathway genes, SOS3 was transiently upregulated to twofold levels in the double mutant after $3 \mathrm{~h} \mathrm{NaCl}$ treatment and returned to the basal level at $6 \mathrm{~h}$, while SOS2 transcripts gradually accumulated to threefold levels in the double mutant compared to WT at $6 \mathrm{~h}$ (Figures 8A,B). SOS1 transcripts accumulated to 1.8 -fold in WT both at 3 and $6 \mathrm{~h}$ after $\mathrm{NaCl}$ treatment (Figure 8C). In both the single mutants, they accumulated to fourfold levels at $3 \mathrm{~h}$ after $\mathrm{NaCl}$ treatment and returned to twofold levels as similar as WT (Figure 8C). In the double mutant, they reached to five and threefold levels, respectively, at 3 and $6 \mathrm{~h}$ compared to those of non-stressed WT (Figure 8C). Upregulation of $\mathrm{NHX} 1$ occurred at $6 \mathrm{~h}$ after $\mathrm{NaCl}$ treatment only in the double mutant, whereas no change in HKT1 expression was observed in any plants after $\mathrm{NaCl}$ treatment (Figures 8D,E). 


\section{A}

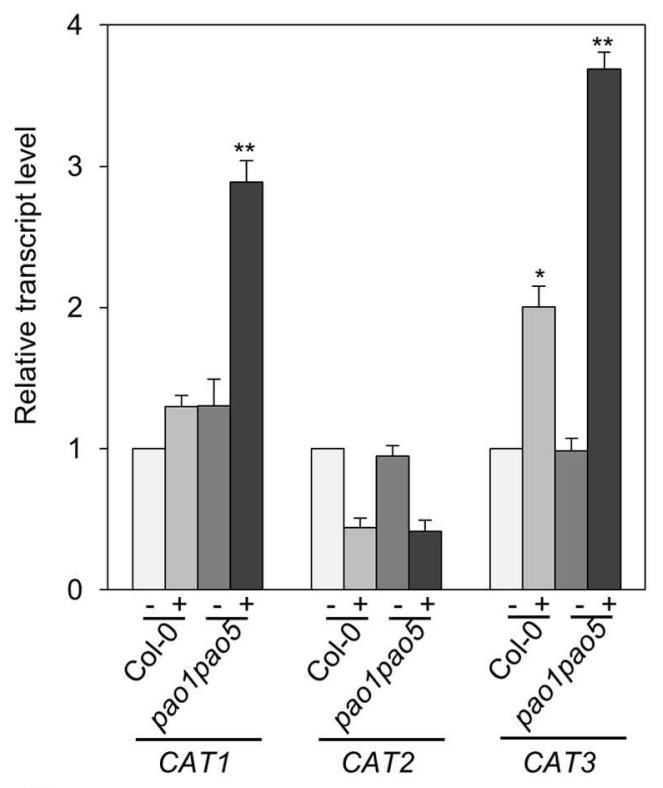

C



FIGURE 7 | Expressional changes of CAT, APX, and SOD genes in WT and pao1 pao5 mutant upon high salt stress. (A) CAT genes; (B) $A P X$ genes; (C) SOD genes. (-) control; (+) treated with $100 \mathrm{mM} \mathrm{NaCl}$ for $6 \mathrm{~h}$. Asterisk indicates significant difference: ${ }^{*} P<0.05$, ${ }^{* *} P<0.01$.

The second pathway is an ABA-dependent signaling pathway that includes several transcription factors (TFs), such as AREB1, AREB2, and the downstream component RD29B (Fujita et al., 2011). The third pathway is an ABA-independent pathway that includes several TFs, such as CBFs, and the CBFs' target components RD29A and COR15A. Among ABA-dependent signaling pathway genes, $A R E B 1$ transcripts accumulated 15- and 20 -fold in WT at 3 and $6 \mathrm{~h}$ salt treatment, while they reached to 32 and 48-fold levels in the double mutant (Figure 9A).
A similar trend was observed for the other bZIP gene, AREB2; i.e., it was induced to two and fourfold levels in WT at 3 and $6 \mathrm{~h}$, respectively, upon $\mathrm{NaCl}$ treatment, whereas in the double mutant the transcript levels rose to 3.8 and 8.9 -fold levels at 3 and $6 \mathrm{~h}$ after $\mathrm{NaCl}$ treatment (Figure 9B). Expression profiles of $R D 29 B, R D 22$, and $R A B 18$ upon salt treatment were quite similar to that of $A R E B 1$ (Figures 9C,E,F). At 6 h-salt treatment, $R D 29 B$ transcripts increased 16-fold in WT, while in the double mutant they reached to 92-fold levels (Figure 9C). RD22 and $R A B 18$ 



(h)

FIGURE 8 | Changes in the expression of genes involved in the SOS-signaling pathway (A-C) and Na transporter genes (D,E) in WT, pao1, pao5, and pao1 pao5 upon high salt stress. Asterisk indicates significant difference: ${ }^{*} P<0.05,{ }^{* *} P<0.01,{ }^{* * *} P<0.001$.

were up-regulated to 25 and 27 -fold levels at $6 \mathrm{~h}$ in WT, while their transcripts reached to 120 and 54-fold levels in the double mutant (Figures 9E,F). COR15B was more quickly induced by salt treatment. In WT, the transcripts accumulated 23 and 13 -fold at 3 and $6 \mathrm{~h}$ salt treatment, and in the double mutant they reached to 56 and 24-fold levels at 3 and $6 \mathrm{~h}$ treatment (Figure 9D). In the ABA-independent pathway, CBF3 was induced at 2-2.6fold levels in WT, while it was induced to 4.5-6-fold levels in the double mutant (Figure 9G). We tested the expression of four $C B F$ s. Of them, only $C B F 3$ was upregulated by $\mathrm{NaCl}$ treatment (Supplementary Figure S7). The downstream target genes, RD29A and COR15A, of CBF3 were also induced at 45-95fold levels and 70-75-fold levels in WT and 100-250-fold levels and 175-200-fold levels in the double mutant (Figures 9H,I).

\section{DISCUSSION}

Here we documented that the Arabidopsis mutant plant, pao1 pao5, which lost cytoplasmic PAO activity is tolerant to high salt and drought stresses through the activation of subsets of defenserelated genes and the reduction of reactive oxygen species (ROS) production.

In this double mutant as well as in each single mutant, pao1 and pao5, intake of $\mathrm{Na}$ ions was reduced to $\sim 75 \%$ of that in WT (Figure 3). The expression of AtHKT1, which controls $\mathrm{Na}^{+}$ entry into plant roots (Rus et al., 2001), was comparable among WT, pao1, pao5 and the double mutant (Figure 8E), and the expression of AtSOS1, which encodes a $\mathrm{Na}^{+} / \mathrm{H}^{+}$antiporter in plasma membrane (Zhu, 2002), was higher in both the single mutants and the double mutant in relative to that of WT (Figure 8C). If the respective transcript levels of the above transporter genes reflect their transporter activity, reduction of $\mathrm{Na}$ intake in the pao1, pao5 and pao1 pao5 is reasonable. However, the reduced $\mathrm{Na}$ intake does not simply explain the tolerant phenotype of the double mutant because each single mutants were salt-sensitive (Supplementary Figure S1). Two other SOS pathway members, AtSOS2 and AtSOS3, were induced at higher levels in the double mutant compared to WT while their induction profiles differed (Figures 8A,B). Cross-talk between 
A

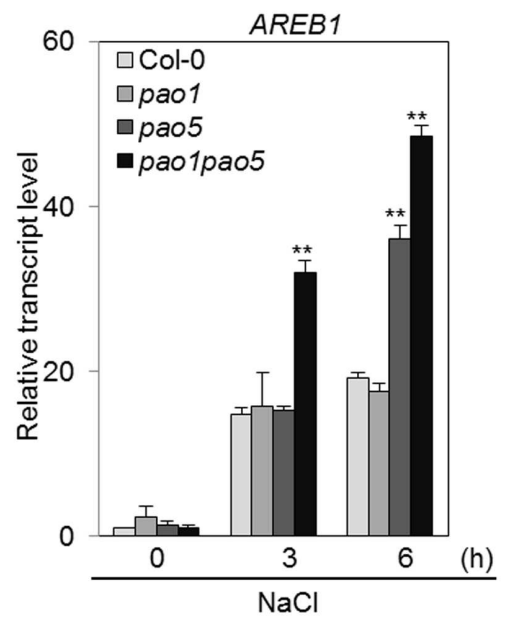

D



G

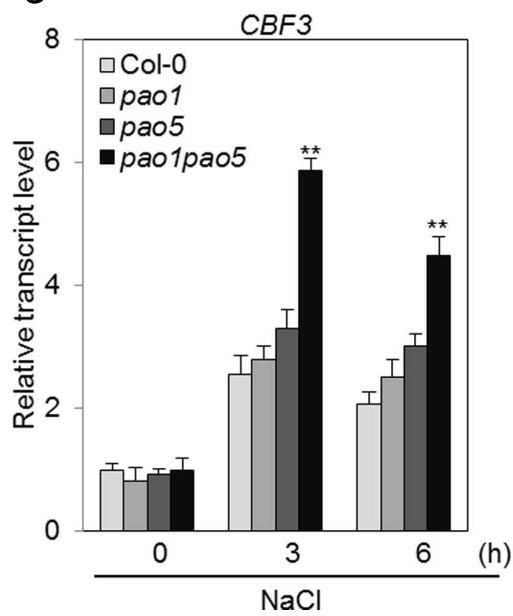

B

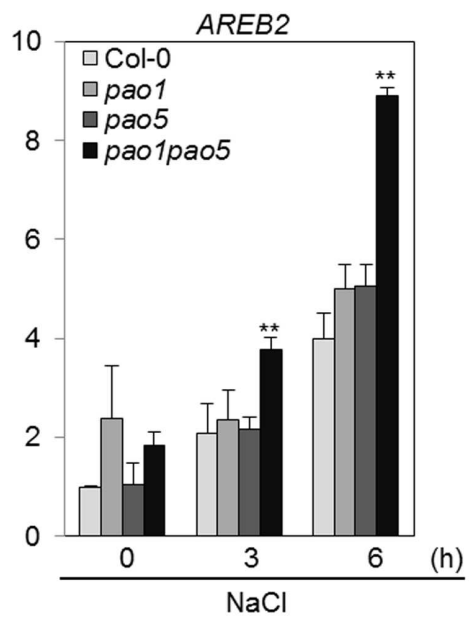

E

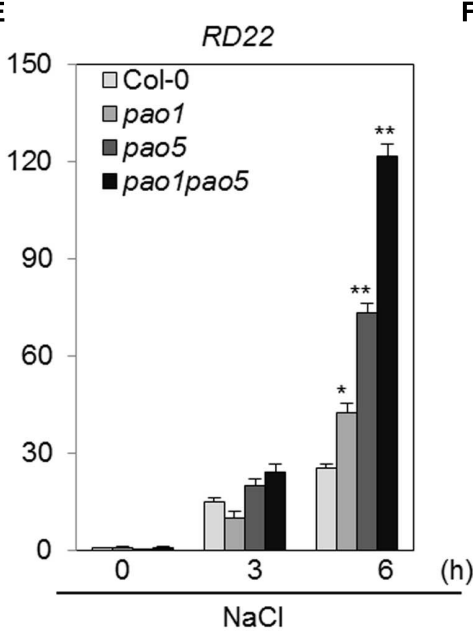

(h)

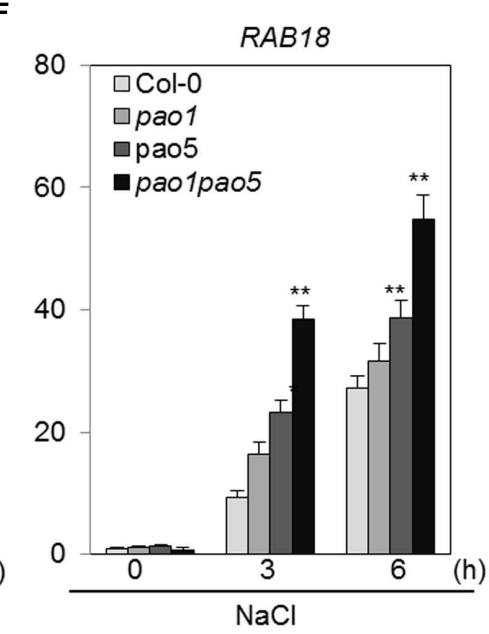

C

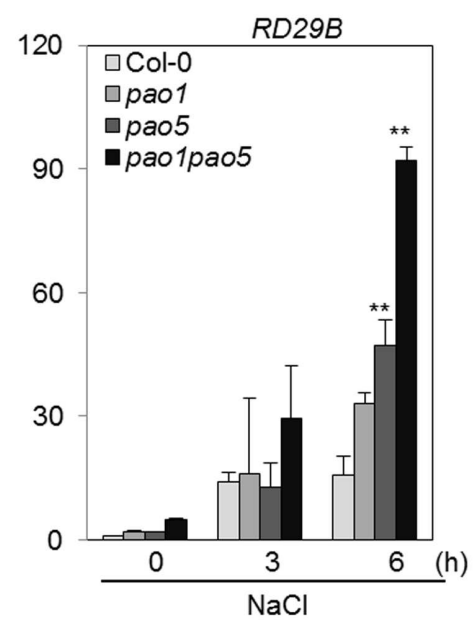

(h) 
AtSOS2 and AtNHX1 (Apse et al., 1999; Yamaguchi et al., 2013, references therein) was evidenced (Qiu et al., 2004; Batelli et al., 2007). In sos 2 mutant, tonoplast $\mathrm{Na}^{+} / \mathrm{H}^{+}$exchange activity which is performed by AtNHX1 was greatly reduced. Addition of activated SOS2 increased tonoplast $\mathrm{Na}^{+} / \mathrm{H}^{+}$exchange activity in vesicles isolated from sos2 (Qiu et al., 2004). AtNHX1 transcripts increased to fourfold levels upon salt treatment only in pao1 pao5 mutant but not in WT, pao1 and pao5 (Figure 8D). Since PAs can activate $\mathrm{Ca}^{2+}$-channels and modulate $\mathrm{H}^{+}$-ATPase pump activity (Pottosin et al., 2014), it is likely that AtNHX1 activity and the rate of cytoplasmic $\mathrm{Na}^{+}$sequestration into the vacuole are higher in the double mutant than in the WT. Higher $\mathrm{Na}^{+}$ sequestration to vacuole may partially explain the salt tolerant phenomenon of the double mutant. Plants respond to high salinity by activating abscisic acid (ABA)-dependent and ABAindependent signaling pathways comprising regulatory genes like TF (Yoshida et al., 2014). Among the genes in the ABAdependent pathway, at least two key TF genes, AREB1 and AREB2 (Yoshida et al., 2010), and the target genes RD29B and RAB18 were significantly induced in the double mutant, and the other ABA-responsive gene $R D 22$, which is regulated by $\mathrm{RD} 22 \mathrm{BP} 1$ (MYC2; Fujita et al., 2011; Osakabe et al., 2014), was induced at the higher levels in the double mutant (Figures 9A-C,E). Of the ABA-independent pathway genes, CBF3/DREB1A and its targets, $R D 29 A$ and $C O R 15 A$, were also upregulated in the double mutant (Figures 9G-I). The enhanced expression of those defense-related genes in the double mutant may also help toward explaining why it was $\mathrm{NaCl}$ tolerant compared to WT, pao1 and pao5.

The reason why the hyper-induction of subsets of defense genes occurs in the double mutant is still covered. AtPAO5 functions in T-Spm catabolism in Arabidopsis (Kim et al., 2014). In the pao5 single mutant, T-Spm levels were twofold higher compared with those in WT (Kim et al., 2014). The recombinant AtPAO1 favored T-Spm over the other PAs (Takahashi et al., 2010). In fact, pao1 pao5 mutant contained $\sim 2.8$-fold higher T-Spm compared to WT (Supplementary Figure S5C). Exogenously applied T-Spm is able to induce the defense-related genes in Arabidopsis (Sagor et al., 2012). Therefore, endogenously accumulated T-Spm itself or a combination of T-Spm and unidentified other factor(s) may contribute as signaling molecule(s) for the gene induction. This point needs to be addressed in the future.

ROS such as $\mathrm{H}_{2} \mathrm{O}_{2}$ and $\mathrm{O}_{2}{ }^{-}$have two 'faces': one is acting as toxic by-products of aerobic metabolism and the other is functioning as signaling molecules to control various processes, such as programmed cell death (PCD) and biotic/abiotic stress responses (Mittler, 2002; Miller et al., 2010). PAOs are $\mathrm{H}_{2} \mathrm{O}_{2}$ forming enzymes (Mittler, 2002; Cona et al., 2006; Kusano et al., 2015). Actually it was shown that $\mathrm{ROS}\left(\mathrm{H}_{2} \mathrm{O}_{2}\right)$ produced via a PAO action emit a signal to induce $\mathrm{PCD}$ in tobacco cell culture (Yoda et al., 2006). It was also reported that PAs control ROS homeostasis during salt stress in plants (Saha et al., 2015). Total PA contents in the double mutant were a bit higher $(45.26 \mathrm{nmol} / \mathrm{g} \mathrm{FW})$, especially T-Spm, than in WT $(42.81 \mathrm{nmol} / \mathrm{g} \mathrm{FW})$ after salt treatment (Supplementary
Figure S5). Basal enzymatic activities of CAT and POX in the double mutant were $\sim 20-30 \%$ higher than those in WT (Figure 6B), whereas those of APX and SOD were comparable in WT and the double mutant (Figure 6B). Whether the higher CAT and POX activities contribute to the enhanced salinity tolerance of pao1pao5 mutant is unclear. To discuss about the potency of each PA to regulate ROS homeostasis or control antioxidant enzyme activity, further works are required.

The reduced ROS, $\mathrm{H}_{2} \mathrm{O}_{2}$, and $\mathrm{O}_{2}^{-}$, production in pao1 pao5 compared with those in $\mathrm{WT}$ upon salt treatment was confirmed quantitatively (Figures $4 \mathrm{~B}, \mathrm{C}$ ) and qualitatively (Figure 5). Intriguingly histochemical staining method showed that net production of $\mathrm{H}_{2} \mathrm{O}_{2}$ and $\mathrm{O}_{2}{ }^{-}$was clearly lower in the double mutant compared with those in WT, pao1, pao5 (Figure 5) and in the other double mutant pao2 pao4 (Supplementary Figure S6). This reduced ROS production may partially explain the different response against salt stress among WT, each single mutants and pao1 pao5 mutant.

Lastly, in keeping with this topic, we have to refer the works done by Moschou et al. (2008a): they generated transgenic tobacco plants overexpressing maize-derived $P A O$. Those transgenic plants were unable to cope with oxidative stresses induced by methyl viologen, menadione, and exogenous $\mathrm{H}_{2} \mathrm{O}_{2}$ (Moschou et al., 2008a). Then, they generated transgenic tobacco plants in which the expression of the apoplastic PAO gene was downregulated by an anti-sense method: those plants exhibited increased biomass production on MS medium supplemented with $100 \mathrm{mM}$ or $200 \mathrm{mM} \mathrm{NaCl}$ (Moschou et al., 2008b). They interpreted that, upon salt stress, plants secreted Spd into apoplastic space, which was catabolized by apoplastic PAO and produced $\mathrm{H}_{2} \mathrm{O}_{2}$. The anti-sense PAO plant produced less $\mathrm{H}_{2} \mathrm{O}_{2}$ and exhibited less PCD, on the other hand, the tobacco plant overexpressing the apoplastic $\mathrm{PAO}$ gene produced higher levels of $\mathrm{H}_{2} \mathrm{O}_{2}$ but failed to induce stress-responsive genes.

In Arabidopsis, there are five AtPAO genes. Of them, AtPAO1, AtPAO2, and AtPAO3 were responsive to salt stress, whereas AtPAO4 and AtPAO5 were not (Supplementary Figure S8). AtPAO1 is expressed in the transition region between the meristematic and the elongation zone of roots and anther tapetum. Its expression is also ABA responsive, especially in root tip (Fincato et al., 2012). Especially AtPAO1 seemed to be involved in salt stress response. Since the pao1 pao5 mutant completes its life cycle, the loss of cytoplasmic PAO activity does not disturb full development. It is of interest whether other plants silencing cytoplasmic PAO pathway become salt and/or drought tolerant. If it is the case, it provides an alternative way to generate salt/drought tolerant plants.

\section{AUTHOR CONTRIBUTIONS}

GS, SZ, SK, TB, and TK designed the experiments. GS, SZ, SK, SS and TB performed the experiments. 
GS, SZ, SK, SS analyzed the data. TB and TK wrote the paper.

\section{ACKNOWLEDGMENTS}

Dr. Chihiro Inoue is acknowledged for guiding us on the use of the ICP spectroscope. This work was supported by grants from the Japan Society for the Promotion of Science (JSPS) to TK

\section{REFERENCES}

Ahou, A., Martignago, D., Alabdallah, O., Tavazza, R., Stano, P., Macone, A., et al. (2014). A plant spermine oxidase/dehydrogenase regulated by the proteasome and polyamines. J. Exp. Bot. 65, 1585-1603. doi: 10.1093/jxb/eru016

Alcázar, R., Altabella, T., Marco, F., Bortolotti, C., Reymond, M., Koncz, C., et al. (2010). Polyamines: molecules with regulatory functions in plant abiotic stress tolerance. Planta 231, 1237-1249. doi: 10.1007/s00425-0101130-0

Andronis, E. A., Moschou, P. N., Toumi, I., and Roubelakis-Angelakis, K. A. (2014). Peroxisomal polyamine oxidase and NADPH-oxidase cross-talk for ROS homeostasis which affects respiration rate in Arabidopsis thaliana. Front. Plant Sci. 5:132. doi: 10.3389/fpls.2014.00132

Angelini, R., Tisi, A., Rea, G., Chen, M. M., Botta, M., Federico, R., et al. (2008). Involvement of polyamine oxidase in wound healing. Plant Physiol. 146, 162-177. doi: 10.1104/pp.107.108902

Apse, M. P., Aharon, G. S., Snedden, W. A., and Blumwald, E. (1999). Salt tolerance conferred by overexpression of a vacuolar $\mathrm{Na}^{+} / \mathrm{H}^{+}$antiport in Arabidopsis. Science 285, 1256-1258. doi: 10.1126/science.285.5431.1256

Bagni, N., and Tassoni, A. (2001). Biosynthesis, oxidation and conjugation of aliphatic polyamines in higher plants. Amino Acids 20, 301-317. doi: 10.1007/s007260170046

Batelli, G., Verslues, P. E., Agius, F., Qiu, Q., Fujii, H., Pan, S., et al. (2007). SOS2 promotes salt tolerance in part by interacting with the vacuolar $\mathrm{H}+$ ATPase and upregulating its transport activity. Mol. Cell Biol. 27, 7781-7790. doi: 10.1128/MCB.00430-07

Beers, R. F. Jr., and Sizer, I. W. (1952). A spectrophotometric method for measuring the breakdown of hydrogen peroxide by catalase. J. Biol. Chem. 195, 133-140.

Berberich, T., Sagor, G. H. M., and Kusano, T. (2015). "Polyamines in plant stress response," in Polyamine: A Universal Molecular Nexus for Growth, Survival and Specialised Metabolism, eds T. Kusano and H. Suzuki (Berlin: Springer), $155-168$.

Capell, T., Bassie, L., and Christou, P. (2004). Modulation of the polyamine biosynthetic pathway in transgenic rice confers tolerance to drought stress. Plant Biol. 101, 9909-9914.

Cohen, S. S. (1998). A Guide to the Polyamines. Oxford: Oxford University Press.

Cona, A., Rea, G., Angelini, R., Federico, R., and Tavladoraki, P. (2006). Functions of amine oxidases in plant development and defense. Trends Plant Sci. 11, 80-88. doi: 10.1016/j.tplants.2005.12.009

Doke, N. (1983). Involvement of superoxide anion generation in the hypersensitive response of potato tuber tissues to infection with an incompatible race of Phytophtora infestans and the hyphal wall components. Physiol. Plant Pathol. 23, 345-357. doi: 10.1016/0048-4059(83) 90020-6

Federico, R., Cona, A., Angelini, R., Schininà, M. E., and Giartosio, A. (1990). Characterization of maize polyamine oxidase. Phytochemistry 29, 2411-2414. doi: 10.1016/0031-9422(90)85157-B

Fincato, P., Moschou, P. N., Ahou, A., Angelini, R., Roubelakis-Angelakis, K. A., Federico, R., et al. (2012). The members of Arabidopsis thaliana PAO gene family exhibit distinct tissue- and organ-specific expression pattern during seedling growth and flower development. Amino Acids 42, 831-841. doi: 10.1007/s00726-011-0999-7

Fincato, P., Moschou, P. N., Spedaletti, V., Tavazza, R., Angelini, R., Federico, R., et al. (2011). Functional diversity inside the Arabidopsis polyamine oxidase gene family. J. Exp. Bot. 62, 1155-1168. doi: 10.1093/jxb/erq341
(15K14705, 2604081). GS was supported by a JSPS postdoctoral fellowship for foreign researchers.

\section{SUPPLEMENTARY MATERIAL}

The Supplementary Material for this article can be found online at: http://journal.frontiersin.org/article/10.3389/fpls.2016.00214

Fuell, C., Elliot, K. A., Hanfrey, C. C., Franceschetti, M., and Michael, A. J. (2010). Polyamine biosynthetic diversity in plants and algae. Plant Physiol. Biochem. 48, 513-520. doi: 10.1016/j.plaphy.2010.02.008

Fujita, Y., Fujita, M., Shinozaki, K., and Yamaguchi-Shinozaki, K. (2011). ABA-mediated transcriptional regulation in response to osmotic stress in plants. J. Plant Res. 124, 509-525. doi: 10.1007/s10265-0110412-3

Groppa, M. D., and Benavides, M. P. (2008). Polyamines and abiotic stress: recent advances. Amino Acids 34, 35-45. doi: 10.1007/s00726-0070501-8

Hanfrey, C., Sommer, S., Mayer, M. J., Burtin, D., and Michael, A. J. (2001). Arabidopsis polyamine biosynthesis: absence of ornithine decarboxylase and the mechanism of arginine decarboxylase activity. Plant J. 27, 551-560. doi: 10.1046/j.1365-313X.2001.01100.x

Ji, H., Pardo, J. M., Batelli, G., Oosten, M. J. V., Bressan, R. A., and Li, X. (2013). The salt overly sensitive (SOS) pathway: established and emerging roles. Mol. Plant 6, 275-286. doi: 10.1093/mp/sst017

Kakehi, J., Kuwashiro, Y., Niitsu, M., and Takahashi, T. (2008). Thermospermine is required for stem elongation in Arabidopsis thaliana. Plant Cell Physiol. 49, 1342-1349. doi: 10.1093/pcp/pcn109

Kamada-Nobusada, T., Hayashi, M., Fukazawa, M., Sakakibara, H., and Nishimura, M. (2008). A putative peroxisomal polyamine oxidase, AtPAO4, is involved in polyamine catabolism in Arabidopsis thaliana. Plant Cell Physiol. 49, 1272-1282. doi: 10.1093/pcp/pcn114

Kim, D. W., Watanabe, K., Murayama, C., Izawa, S., Niitsu, M., Michael, A. J., et al. (2014). Polyamine oxidase5 regulates Arabidopsis thaliana growth through a thermospermine oxidase activity. Plant Physiol. 165, 1575-1590. doi: 10.1104/pp.114.242610

Knott, J. M., Romer, P., and Sumper, M. (2007). Putative spermine synthases from Thalassiosira pseudonana and Arabidopsis thaliana synthesize thermospermine rather than spermine. FEBS Lett. 581, 3081-3086. doi: 10.1016/j.febslet.2007.05.074

Kusano, T., Berberich, T., Tateda, C., and Takahashi, Y. (2008). Polyamines: essential factors for growth and survival. Planta 228, 367-381. doi: 10.1007/s00425-008-0772-7

Kusano, T., Kim, D. W., Liu, T., and Berberich, T. (2015). "Polyamine catabolism in plants," in Polyamine: A Universal Molecular Nexus for Growth, Survival and Specialised Metabolism, eds T. Kusano and H. Suzuki (Berlin: Springer), 77-88.

Liu, J., and Liu, Y. L. (2004). The relations between polyamine types and forms and polyamine oxidase activities in barley seedlings under salt stress. J. Plant Physiol. Mol. Biol. 30, 141-146.

Liu, J.-H., Wang, W., Wu, H., Gong, X., and Moriguchi, T. (2015). Polyamines function in stress tolerance: from synthesis to regulation. Front. Plant Sci. 6:827. doi: 10.3389/fpls.2015.00827

Mahajan, S., Pandey, G. K., and Tuteja, N. (2008). Calcium- and salt-stress signaling in plants: shedding light on SOS pathway. Arch. Biochem. Biophys. 471, 146-158. doi: 10.1016/j.abb.2008.01.010

Mattoo, A. K., Minocha, S. C., Minocha, R., and Handa, A. K. (2010). Polyamines and cellular metabolism in plants: transgenic approaches reveal different responses to diamine putresciner versus higher polyamines spermidine and spermine. Amino Acids 38, 405-413. doi: 10.1007/s00726-0090399-4

McCord, J. M., and Fridovich, I. (1969). Superoxida dismutase an enzymic function for erythrocuprein (hemocuprein). J. Biol. Chem. 244, 6049-6055.

Messner, B., and Boll, M. (1994). Cell suspension cultures of spruce (Picea abies): inactivation of extracellular enzymes by fungal elicitor-induced transient release 
of hydrogen peroxide (oxidative burst). Plant Cell Tissue Organ. Cult. 39, 69-78. doi: 10.1007/BF00037594

Miller, G. A. D., Suzuki, N., Ciftci-Yilmaz, S., and Mittler, R. (2010). Reactive oxygen species homeostasis and signaling during drought and salinity stresses. Plant Cell Environ. 33, 453-467. doi: 10.1111/j.1365-3040.2009. 02041.x

Minocha, R., Majumdar, R., and Minocha, S. C. (2014). Polyamines and abiotic stress in plants: a complex relationship. Front. Plant Sci. 5:175. doi: 10.3389/fpls.2014.00175

Mittler, R. (2002). Oxidative stress, antioxidants and stress tolerance. Trends Plant Sci. 7, 405-410. doi: 10.1016/S1360-1385(02)02312-9

Mo, H., Wang, X., Zhang, Y., Zhang, G., Zhang, J., and Ma, Z. (2015). Cotton polyamine oxidase is required for spermine and camalexin signaling in the defence response to Verticillium dahlie. Plant J. 83, 962-975. doi: 10.1111/tpj.12941

Moschou, P. N., Delis, I. D., Paschalidis, K. A., and Roubelakis-Angelakis, K. A. (2008a). Transgenic tobacco plants overexpressing polyamine oxidase are not able to cope with oxidative burst generated by abiotic factors. Physiol. Plant 133, 140-156. doi: 10.1111/j.1399-3054.2008.01049.x

Moschou, P. N., Paschalidis, K. A., Delis, I. D., Andriopoulou, A. H., Lagiotis, G. D., Yakoumakis, D. I., et al. (2008b). Spermidine exodus and oxidation in the apoplast induced by abiotic stress is responsible for $\mathrm{H}_{2} \mathrm{O}_{2}$ signatures that direct tolerance responses in tobacco. Plant Cell 20, 1708-1724. doi: 10.1105/tpc.108.059733

Moschou, P. N., Sanmartin, M., Andriopoulou, A. H., Rojo, E., Sanchez-Serrano, J. J., and Roubelakis-Angelakis, K. A. (2008c). Bridging the gap between plant and mammalian polyamine catabolism: a novel peroxisomal polyamine oxidase responsible for a full back-conversion pathway in Arabidopsis. Plant Physiol. 147, 1845-1857. doi: 10.1104/pp.108.123802

Moschou, P. N., Wu, J., Cona, A., Tavladoraki, P., Angelini, R., and RoubelakisAngelakis, K. A. (2012). The polyamines and their catabolic products are significant players in the turnover of nitrogenous molecules in plants. J. Exp. Bot. 63, 5003-5015. doi: 10.1093/jxb/ers202

Naka, Y., Watanabe, K., Sagor, G. H. M., Niitsu, M., Pillai, A., Kusano, T., et al. (2010). Quantitative analysis of plant polyamines including thermospermine during growth and salinity stress. Plant Physiol. Biochem. 48, 527-533. doi: 10.1016/j.plaphy.2010.01.013

Nakano, Y., and Asada, K. (1987). Purification of ascorbate peroxidase in spinach chloroplasts; its inactivation in ascorbate-depleted medium and reactivation by monodehydroascorbate radical. Plant Cell Physiol. 28, 131-140.

Niitsu, M., and Samejima, K. (1986). Synthesis of a series of linear pentaamines with three and four methylene chain intervals. Chem. Pharm. Bull. (Tokyo) 34, 1032-1038. doi: 10.1248/cpb.34.1032

Osakabe, Y., Yamaguchi-Shinozaki, K., Shinozaki, K., and Tran, L.-S. (2014). ABA control of plant macroelement membrane transport system in response to water deficit and high salinity. New Phytol. 202, 35-49. doi: 10.1111/nph.12613

Planas-Portell, J., Gallart, M., Tiburcio, A. F., and Altabella, T. (2013). Coppercontaining amine oxidases contribute to terminal polyamine oxidation in peroxisomes and apoplast of Arabidopsis thaliana. BMC Plant Biol. 13:109. doi: 10.1186/1471-2229-13-109

Pottosin, I., Velarde-Buendia, A. M., Bose, J., Fuglsang, A. T., and Shabala, S. (2014). Polyamines cause plasma membrane depolarization, activate $\mathrm{Ca}^{2+}$-, and modulate $\mathrm{H}^{+}$-ATPase pump activity in pea roots. J. Exp. Bot. 65, 2463-2472. doi: 10.1093/jxb/eru133

Qiu, Q.-S., Guo, Y., Quintero, F. J., Pardo, J. M., Schumaker, K. S., and Zhu, J.-K. (2004). Regulation of vacuolar $\mathrm{Na}^{+} / \mathrm{H}^{+}$exchange in Arabidopsis thaliana by the Salt-Overly-Sensitive (SOS) pathway. J. Biol. Chem. 279, 207-215. doi: 10.1074/jbc.M307982200

Roach, T., Colville, L., Beckett, R. P., Minibayeva, F. V., Havaux, M., and Kranner, I. (2015). A proposed interplay between peroxidase, amine oxidase and lipoxygenase in the wounding-induced oxidative burst in Pisum sativum. Phytochemistry 112, 130-138. doi: 10.1016/j.phytochem.2014.06.003

Romero-Puertas, C. M., Rodriguez-Serrano, F. J., Corpas, M., Gomez, L. A., Del Rio, L., and Sandalio, M. (2004). Cadmium induced subcellular accumulation of $\mathrm{O}_{2}$ - and $\mathrm{H}_{2} \mathrm{O}_{2}$ in pea leaves. Plant Cell Environ. 27, 1122-1134. doi: 10.1111/j.1365-3040.2004.01217.x

Rus, A., Yokoi, S., Sharkhuu, A., Reddy, M., Lee, B., Matsumoto, T. K., et al. (2001). AtHKT1 is a salt tolerance determinant that controls $\mathrm{Na}^{+}$entry into plant roots. Proc. Natl. Acad. Sci. U.S.A. 98, 14150-14155. doi: 10.1073/pnas.2415 01798

Sagor, G. H. M., Inoue, M., Kim, D. W., Kojima, S., Niitsu, M., Berberich, T., et al. (2015). The polyamine oxidase from lycophyte Selaginella lepidophylla (SelPAO5), unlike that of angiosperms, back-converts thermospermine to norspermidine. FEBS Lett. 589, 3071-3078. doi: 10.1016/j.febslet.2015.xyb08.045

Sagor, G. H. M., Takahashi, H., Niitsu, M., Takahashi, Y., Berberich, T., and Kusano, T. (2012). Exogenous thermospermine has an activity to induce a subset of the defense genes and restrict cucumber mosaic virus multiplication in Arabidopsis thaliana. Plant Cell Rep. 31, 1227-1232. doi: 10.1007/s00299-0121243-y

Saha, J., Brauer, E. K., Sengupta, A., Popescu, S. C., Gupta, K., and Gupta, B. (2015). Polyamines as redox homeostasis regulators during salt stress in plants. Front. Environ. Sci. 3:21. doi: 10.3389/fenvs.2015. 00021

Schmittgen, T. D., and Livak, K. J. (2008). Analyzing real-time PCR data by the comparative CT method. Nat. Protoc. 3, 1101-1108. doi: 10.1038/nprot.2008.73

Tabor, C. W., and Tabor, H. (1985). Polyamines in microorganisms. Microbiol. Rev. 49, 81-99.

Takahashi, Y., Cong, R., Sagor, G. H. M., Niitsu, M., Berberich, T., and Kusano, T. (2010). Characterization of five polyamine oxidase isoforms in Arabidopsis thaliana. Plant Cell Rep. 29, 955-965. doi: 10.1007/s00299-0100881-1

Takano, A., Kakehi, J. I., and Takahashi, T. (2012). Thermospermine is not a minor polyamine in the plant kingdom. Plant Cell Physiol. 53, 606-616. doi: $10.1093 / \mathrm{pcp} / \mathrm{pcs} 019$

Tavladoraki, P., Rossi, M. N., Saccuti, G., Perez-Amador, M. A., Polticelli, F., Angelini, R., et al. (2006). Heterologous expression and biochemical characterization of a polyamine oxidase from Arabidopsis involved in polyamine back conversion. Plant Physiol. 141, 1519-1532. doi: 10.1104/pp.106.080911

Urano, K., Yoshiba, Y., Nanjo, T., Igarashi, Y., Seki, M., Sekiguchi, F., et al. (2003). Characterization of Arabidopsis genes involved in biosynthesis of polyamine in abiotic stress responses and developmental stages. Plant Cell Environ. 26, 1917-1926. doi: 10.1046/j.1365-3040.2003. 01108.x

Wang, W., and Liu, J. H. (2015). Genome-wide identification and expression analysis of the polyamine oxidase gene family in sweet orange (Citrus sinensis). Gene 555, 421-429. doi: 10.1016/j.gene.2014. 11.042

Weigel, D., and Glazebrook, J. (2002). Arabidopsis, A Laboratory Manual. New York, NY: Cold Spring Harbor.

Yamaguchi, K., Takahashi, Y., Berberich, T., Imai, A., Miyazaki, A., Takahashi, T., et al. (2006). The polyamine spermine protects against high salt stress in Arabidopsis thaliana. FEBS Lett. 580, 6783-6788. doi: 10.1016/j.febslet.2006.10.078

Yamaguchi, K., Takahashi, Y., Berberich, T., Imai, A., Takahashi, T., Michael, A., et al. (2007). A protective role for the polyamine spermine against drought stress in Arabidopsis. Biochem. Biophys. Res. Commun. 352, 486-490. doi: 10.1016/j.bbrc.2006.11.041

Yamaguchi, T., Hamamoto, S., and Uozumi, N. (2013). Sodium transport system in plant cells. Front. Plant Sci. 4:410. doi: 10.3389/fpls.2013. 00410

Yoda, H., Hiroi, Y., and Sano, H. (2006). Polyamine oxidase is one of the key elements for oxidative burst to induce programmed cell death in tobacco cultured cells. Plant Physiol. 142, 193-206. doi: 10.1104/pp.106. 080515

Yoshida, T., Fujita, Y., Sayama, H., Kidokoro, S., Maruyama, K., Mizoi, J., et al. (2010). AREB1, AREB2, and ABF3 are master transcription factors that cooperatively regulate ABRE-dependent $\mathrm{ABA}$ signaling involved in drought stress tolerance and require $\mathrm{ABA}$ for full activation. Plant J. 61, 672-685. doi: 10.1111/j.1365-313X.2009. 04092.x

Yoshida, T., Mogami, J., and Yamaguchi-Shinozaki, K. (2014). ABAdependent and ABA-independent signaling in response to osmotic stress in plants. Curr. Opin. Plant Biol. 21, 133-139. doi: 10.1016/j.pbi.2014. 07.009 
Zhu, J. K. (2002). Salt and drought stress signal transduction in plants. Annu. Rev. Plant Biol. 53, 247-273. doi: 10.1146/annurev.arplant.53.091401. 143329

Conflict of Interest Statement: The authors declare that the research was conducted in the absence of any commercial or financial relationships that could be construed as a potential conflict of interest.
Copyright (C) 2016 Sagor, Zhang, Kojima, Simm, Berberich and Kusano. This is an open-access article distributed under the terms of the Creative Commons Attribution License (CC BY). The use, distribution or reproduction in other forums is permitted, provided the original author(s) or licensor are credited and that the original publication in this journal is cited, in accordance with accepted academic practice. No use, distribution or reproduction is permitted which does not comply with these terms. 